\title{
A Critical Review by Teachers on the Online Teaching-Learning during the COVID-19
}

\author{
Malik Mubasher Hassan \\ Dept. of ITE, BGSB University Rajouri, J\&K (India)-185234 \\ E-mail: mubasher2003@gmail.com
}

Tabasum Mirza and Dr. Mirza Waseem Hussain

Dept. of School Education, Govt. of J\&K (India)

Received:29 May 2020; Accepted: 06 July 2020; Published: 08 October 2020

\begin{abstract}
The world has witnessed a sudden change in the teaching-learning processes due to the ongoing pandemic of COVID-19. The worldwide compulsive lockdown for ensuring the preventive measures to stop the spread of this infection has equally affected education sector as other business sectors. As all of us know that quality education is the only long-term rescue for all the challenges and therefore, the need to find out the alternative solution to the traditional classroom teachinglearning is the concern of all stakeholders and the only option found is online mode of teaching-learning, which was somehow already available and had attracted an intense attention during this period. The aim of the paper is to study the teacher's perspective in India about this mode of learning, challenges and issues faced by them in migration to online platform, experience about online tools/platforms used for instructional delivery and their suggestions to improve the process for effective teaching. This study will help in gaining insight towards the possible improvements in the ongoing mode of online teaching and in future situations also. The results obtained based on sample collection through web based questionnaire clearly gives some information, which could be an eye opener for enhancing the implementation of the online teachinglearning among the learners especially teachers, who can further help in implementation of the large. Although, the online mode was already in place and was utilized in blended form to a substantial level in the developed countries, but in developing countries like India, where teachers are not familiar with online platforms/tools, lack of knowledge and skills to handle the online ICT infrastructure in a challenging situation. The results also give an impression about the need of professional development with special focus on digital literacy skills and awareness among the teacher community about the merits of online platforms for the teaching-learning process.
\end{abstract}

Index Terms: Online Teaching-Learning, ICT, and COVID-19.

\section{Introduction}

COVID-19 has come as public health emergency and one of the biggest calamities humanity ever faced[1].The COVID-19 crisis has put the Government and policy makers in dilemma to choose between closing the educational institutions to ensure health and safety with respect to spread of COVID-19 thus saving lives of students and allowing them to function normally to prevent the loss of education to students[2]. But as health and saving lives is the topmost priority for every individual as well as nation more than 190 countries in the world has closed down educational institutions till the situation improves[3]. This will impact $90 \%$ of the total enrolled learners worldwide[4,5]. Indian Government also had to announce lockdown of educational institutions till further orders as number of COVID-19 infection cases are raising in the country. This shutting down of schools, colleges and universities has caused major disruption in the education system. As per UNESCO almost 1.725 billion learners are currently affected worldwide and 320 million are affected in India due to school closures as on 18 may 2020[5]. According to UDISE data, India's educational infrastructure comprises of 1.5 million schools, 250 million students, 9.4 million teachers at the school level, and 50,000 higher education institutions. This constitutes $72 \%$ of the world's student population, if prolonged it can threaten to right to education of children in India[6]. The School learning is an important tool that contributes to overall development of the children. It leads to development of children's social skills, personality development, and development of motor skills by involvement in cocurricular activities. School time is fun time for children as they get to spend time with friends and are inspired and motivated by their teachers. When learners go to school they follow the schedule of learning strictly and work in a disciplined manner[7]. To compensate learning loss due to school closures and minimise its impact on education most of the schools, colleges and universities have moved to alternative form of teaching, learning i.e. online teaching[8]. Even though these alternatives cannot fully compensate the benefits of schooling but it can help learners learn at their flexibility 
while staying home. UNESCO has suggested the six-point strategy for the purpose that involves teachers and communities, stresses on the adoption of appropriate distance learning practices, considering the digital divide, safeguarding vital services and engaging young people [10,11,12]. In developed countries where most of the population is online and schools are already using online modes for teaching shifting to online mode of teaching has not been very difficult, but in emerging countries like India where use of online modes for teaching is not much prevalent this shift has posed many challenges[10]. The first and foremost challenge is availability of digital devices and high speed internet connections in students to participate in online learning ventures[14,15]. India has internet penetration of 36 per cent, internet users per 100 is 78 , fixed broadband subscription per 100 stands at 1.34, and 46 per cent of households have television, use of ICT as an alternative mode of delivery of education in pandemic is not an easy task. Other challenges include like the reliability of electricity supply, and ownership of digital devices. The most important factor affecting online teaching is digital skills of teachers and students[12]. Most of the teachers are seen struggling to teach online and some of them are using easy but not very versatile tools to stay connected with students. Teachers are facing technical issues in creating e-content and in online delivery of instruction[13]. Many teachers feel that learners are less interested during online sessions and don't respond to online assignments, even teachers are distracted with their surroundings during the teaching sessions[18,19,20]. Some experts believe that this crisis will cause paradigm shift in education and will result in development of new technology integrated pedagogy as teachers and students are getting accustomed to use of technology in teaching learning process. While others take this online teaching process as a temporary alternative until classroom teaching is restored properly[21,22]. However online learning has its own challenges and limitations, the main challenges for country like India is the availability of digital infrastructure in remote and rural areas and lack of experience in teachers to use technology based platforms for teaching. This will result in widening of already existing digital divide in the country[16].

The objective of this research is to study the teacher's perspectives about online teaching-learning during the COVID-19 in India. Applications like Zoom used for videoconferencing also pose security concerns to teachers using them increasing fear in teachers for use of digital platforms[17].Some other issues include low internet speed preventing picture, sound clarity which makes delivery of knowledge difficult for both the instructor and the student[18].

Education is the worst hit sector by COVID-19.There is no other suitable option that could be evaluated to replace or compensate classroom teaching in this unanticipated or unpredictable situation where people are uncertain about the resumption of educational activities in the institutions. It may take months or longer until the threat of COVID-19 infections comes to an end and until then people can't risk the lives of their children by sending them to schools. Until then students have to rely on online teaching for their education. various studies going on are suggesting that teachers are facing various issues in teaching online and as the result the teaching process is not very effective. The purpose of this study is to study perspectives of teachers about Online teaching in COVID-19, challenges faced by them in the process, tools/platforms they are comfortable to use, and to consider their suggestions in improvement of the Online teaching platforms. The results of this study can help in improving Online teaching experience of teachers by addressing these issues resulting in effective delivery of quality education.

\section{Objectives}

I. To investigate the challenges faced by teachers in Online teaching

II. To help understand perspective of teachers about online teaching amidst COVID-19.

III. To rate their experience in terms of difficulty about Online platforms of teaching.

IV.To determine the teachers level of exposure to online teaching.

V. To check which tools teachers are using for online teaching.

\section{Background}

The history of this study is very latest, because when the last pandemic occurred there was no such a platform globally that could have been used for teaching-learning across any country or across the world. But since last decade the online teaching has been extremely instrumental in the conflict hit areas. The countries and territories like Libya, Sudan, Iraq, Syria, Afghanistan, Kashmir, Myanmar, Ukraine, and Kenya has been using online teaching despite the several challenges of digital infrastructure like unreliable internet connectivity. There are countries like Yemen, which make use of online technology like mobile-learning for teaching-learning despite infrastructural hiccups [19]. The closure of educational institutes across the world has imposed a bigger challenge to the education system. People from different reputed educational institutions developed a huge e-content and placed on the cloud for almost open access to the people across the globe. The world has been taken under surprise by the COVID-19 and to ensure the health safety, almost all the institutions pertaining to teaching has been closed. People were compelled to adopt online teaching-learning to compensate the educational loss and if it continues the online mode has to be a good alternative for the traditional teaching-learning 
processes.

\section{Literature Survey}

Subashni Appana in her paper "A Review of Benefits and Limitations of Online Learning in the Context of the Student, the Instructor, and the Tenured Faculty" writes about various benefits and limitations of online learning for the student, teacher and other faculty. She listed various benefits of online learning like increased access, improved quality of education, preparing students for knowledge based society, lifelong learning opportunities, etc[20].

Thierry Volery, Deborah Lord in their paper on critical success factors in education explains the tremendous scope of online education for expanding access, alleviating capacity constraints, capitalizing on emergent market opportunities and serving as a catalyst for institutional transformation[21].

Birgit Bomsdorf in is paper on Adaptation of learning spaces: supporting ubiquitous learning writes about the use of ubiquitous computing to support learning anytime from anywhere in various contexts and situations[22].

Sun, A., \& Chen, X. (2016) in his article about “Online education and its effective practice” based on the findings stated that effective online instruction depends upon: 1) creating well-designed course content, enabling motivated interaction between the teacher and students, well-trained and digitally competent instructors 2) creating a sense of online learning community for teaching and learning and 3) use of advanced technology tools/platforms[23].

Huang, R.H., Liu, D.J., Tlili, A., Yang, J.F., Wang, H.H., et al. (2020) in their Handbook on Facilitating Flexible Learning During Educational Disruption writes about flexible online education to continue learning amidst the COVID-19 which has caused a major disruption to the global education[24].

\section{Methodology}

The aim of this survey was to study teacher's perceptions about the online teaching as only possible alternative mode of teaching in ongoing pandemic. The quantitative study used questionnaire as an instrument to collect data. The web based questionnaire was the most appropriate method of collecting the data at the time of lockdown. Data was collected from teachers and lecturers from different institutes of India by online delivery. Data collection procedure included use of questionnaire consisting of close ended multiple questions through which respondents were asked for their experience encountering use of online teaching process at the time of ongoing pandemic as an alternative mode of teaching. The questionnaire for teachers consists of questions that helped to understand their attitudes and perspectives on the use of online teaching and e-content creation. Questions were used to rate their experience and understand their perspective about the use of various online and mobile platforms used for online teaching.

\section{Data analysis}

The survey instrument (questionnaire) was used for data collection. The questionnaire was divided into five sections. Section 1 contains demographic information (name, gender, designation), section 2 was used to study challenges faced by teachers in online delivery of education, section 3 was used to identify the teachers exposure to online teaching, section 4 to assess their perspectives about online teaching and section 5 was used to rate experience of teachers in online teaching in terms of difficulty. The questionnaire consisted of 12 closed ended questions. Teachers were asked about the use of platform/tool they prefer in delivery of education. They were provided with various options which combined tools/platforms like Whatsapp, Zoom, Google classroom, YouTube etc. Last section of questionnaire asked teachers were asked to rate their experience in terms of difficulty using online platforms/tools for delivering education using Likert scale according to the following scale:-
1-Very Easy
2-Easy
3-Difficult
4-Very Difficult.

The respondents were asked to self report their perspectives regarding online education during the COVID-19. Not all questions required a response. The survey was released in the 1st week of May 2020 and was available for ten days to accept responses from the respondents. No incentives were offered to complete the survey. Name of respondent was kept optional to respect anonymity of the teachers who didn't want to mention their name in survey.

All the data collected was organized, cleaned and then analyzed properly. The data analysis uses the frequency procedure to tabulate the counts and calculate the percentages of responses. The data was classified using the self cognitive classifier to analyse its auto and cross correlation. The information retrieved from the analysis depicts the considerations of online teaching during the COVID-19. The quantitative data was then graphically represented in the form of graphs and charts to illustrate relationships between various data elements.

As both authors are teaching and have firsthand experience of online teaching, their personal experiences also contribute towards the research study.

Accuracy in responses to a survey is a measure of trust that is expected from professional community of teachers who are seriously committed towards improvement and evolution of online teaching learning system. We have used online system for delivery of surveys to reach out to maximum teachers amidst pandemic. Research studies in the past suggest 
that online surveys increase the accuracy of responses and respondents are likely to be truthful and comfortable in online mode of answering. We have kept name of teacher as an optional field to retain anonymity and privacy of the respondents so that sensitive questions are answered without the social desirability bias. The accuracy and reliability of the data at entry level has been ensured by cross validation process for demographic variables through comparisons with the correct answers like gender. The other responses can be similarly validated against reliable benchmarks. We have used radio option buttons or Likert scale to collect data to reduce error in entry of responses.

\section{Results and Discussion}

\subsection{Gender}

The $57.1 \%$ of the teachers participating in the online teaching survey are male and $42.9 \%$ of them are female (see Fig.1).

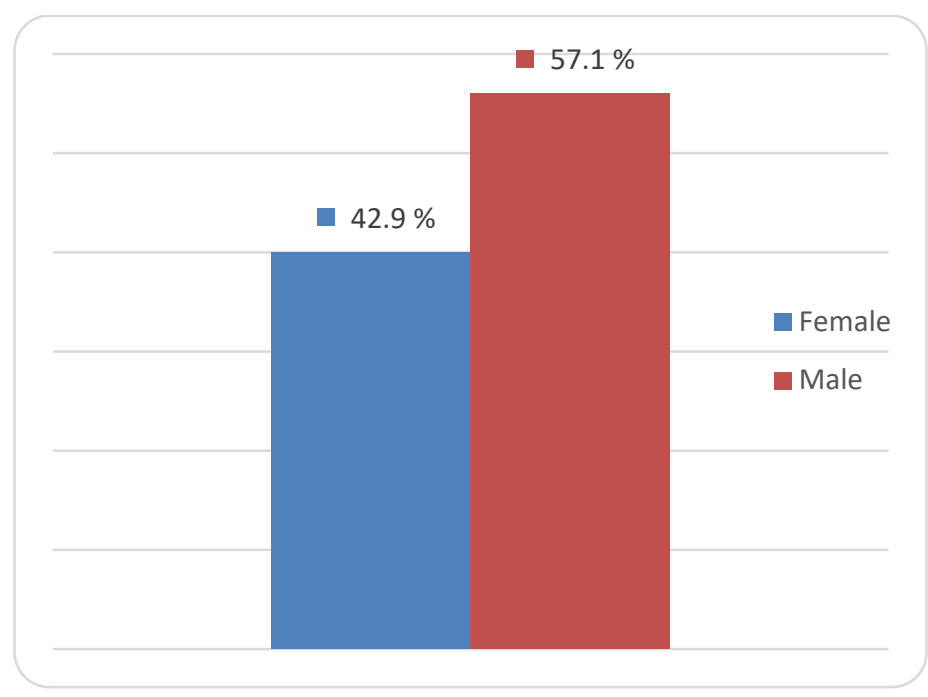

Fig. 1 Gender

6.2 Teachers considering online teaching as a viable alternative to classroom teaching at the time of the ongoing pandemic

The $95.7 \%$ of the teachers considered online teaching as a suitable alternative to classroom teaching at the time of ongoing pandemic (see Fig.2).

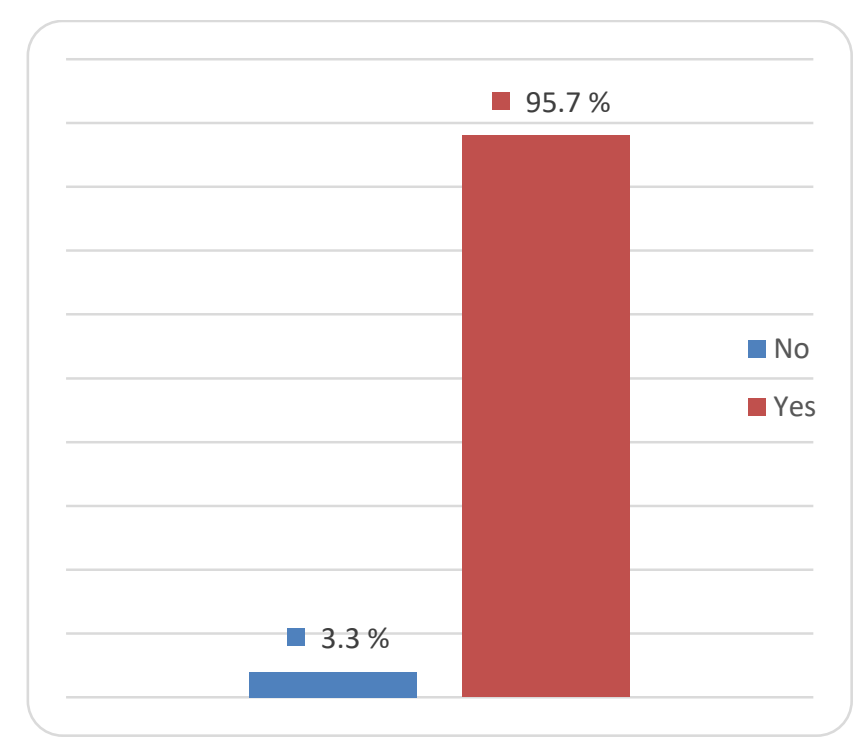

Fig. 2 Teachers consider online teaching as a viable alternative to classroom teaching at the time of the ongoing pandemic 


\subsection{Teachers facing technical issues while delivering online or creating e-content}

73.5\% of the teachers reported that they are facing technical difficulties while delivering online or while creating econtent (see Fig.3).

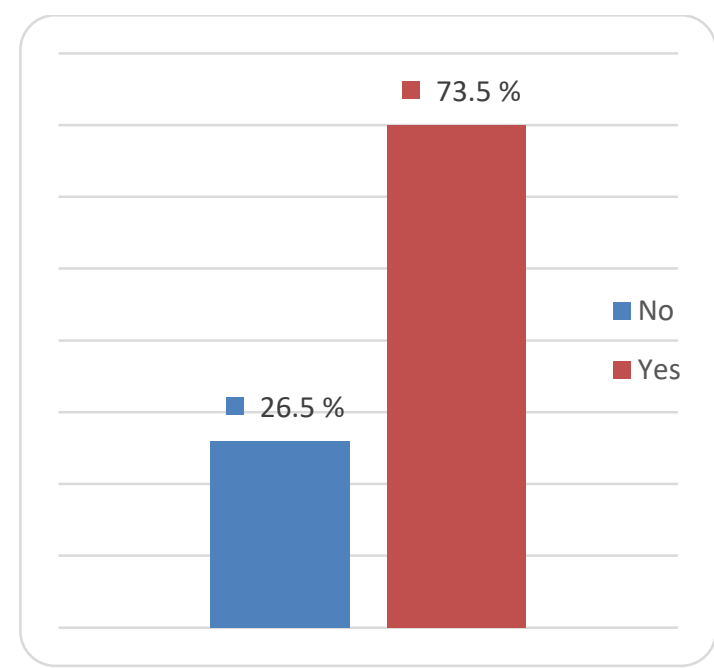

Fig. 3 Teachers facing technical issues while delivering online

\subsection{Teachers facing Internet connectivity issues while delivering online lectures}

Almost $91.7 \%$ of the total teachers participating in the study were facing internet connectivity issues while delivering online lectures. Only 8.3\% of the teachers reported did not faced the Internet connectivity issues (see Fig.4).

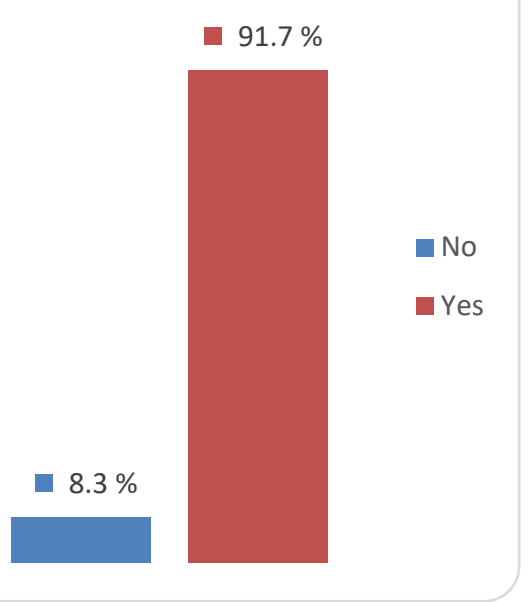

Fig 4 Teachers facing Internet connectivity issues while delivering online lectures

\subsection{Teachers having sufficient computer skills and knowledge to conduct online lectures or create e-content}

Major proportion of the teachers i.e. 55.1\% agreed that they lack sufficient computer skills and knowledge to conduct online lectures or create e content, only $44.9 \%$ of teachers considered they are competent to deliver online teaching or create e-content (see Fig.5). 


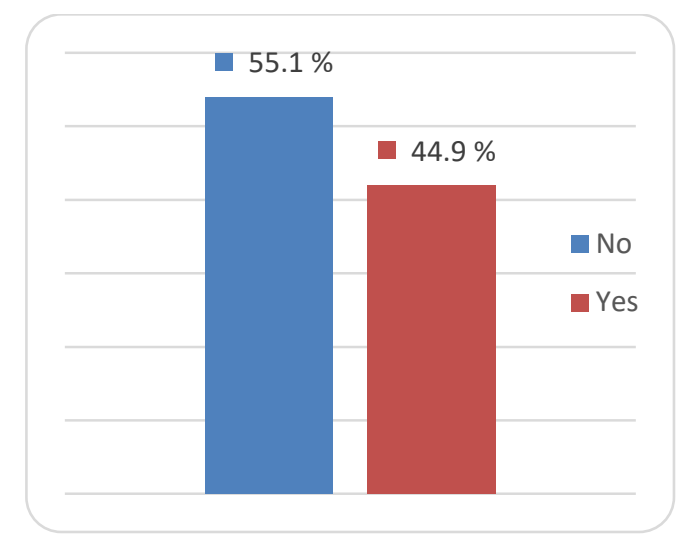

Fig. 5 Teachers having sufficient computer skills and knowledge to conduct online lectures or create e-content

6.6 Teachers feeling the need for training /guidelines on the preparation of online lecture material or using online teaching platforms

$63.5 \%$ of teachers felt the need for training or guidelines for the preparation of online lecture material or using online teaching platforms. About 12.2\% teachers reported that they don't require guidelines or training for preparation of teaching content or use of online platforms $.22 .4 \%$ of teachers said that they may require training or guidelines to help in online teaching (see Fig.6).

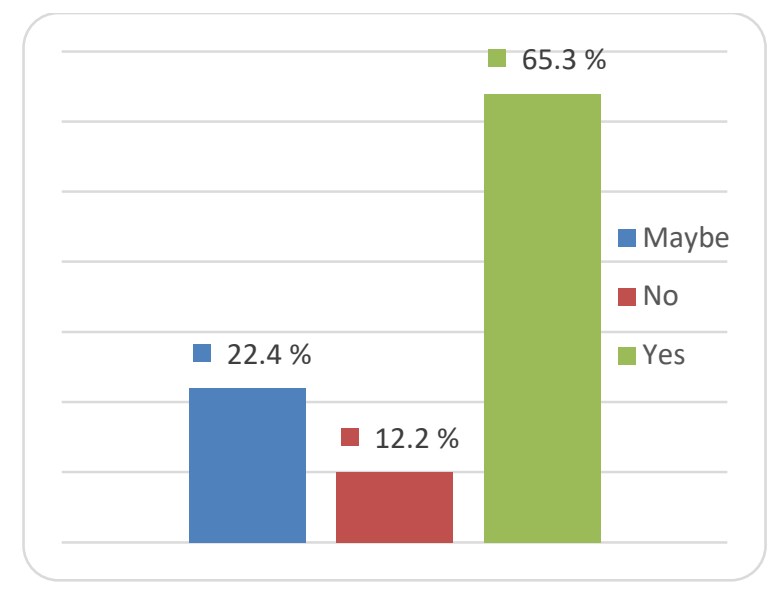

Fig .6 Teachers feel the need for training /guidelines on the preparation of online lecture material or using online teaching platforms

\subsection{Students responding to assignments/project work assigned to them online}

Teachers reported that only $28.6 \%$ of the students respond to assignments or project work assigned to them online by teachers.71.4\% of teachers showed no response or weak response to the assignments or project work assigned to them (see Fig.7).

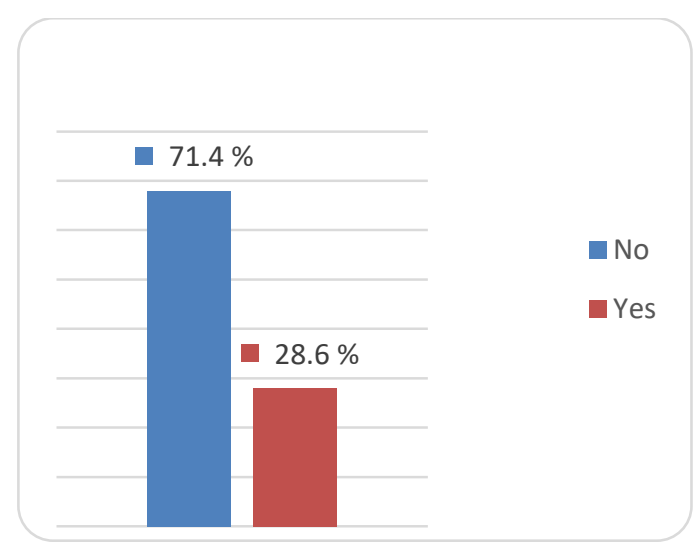

Fig. 7 Students responding to assignments/project work assigned to them online 


\subsection{Teachers considering lack of face to face interaction as a disadvantage in online teaching}

Maximum percentage i.e. 89.6\% considered lack of human touch and face to face interaction as a drawback in online teaching. Only $10.4 \%$ of teachers didn't consider lack of face to face interaction as disadvantage in online teaching (see Fig.8).

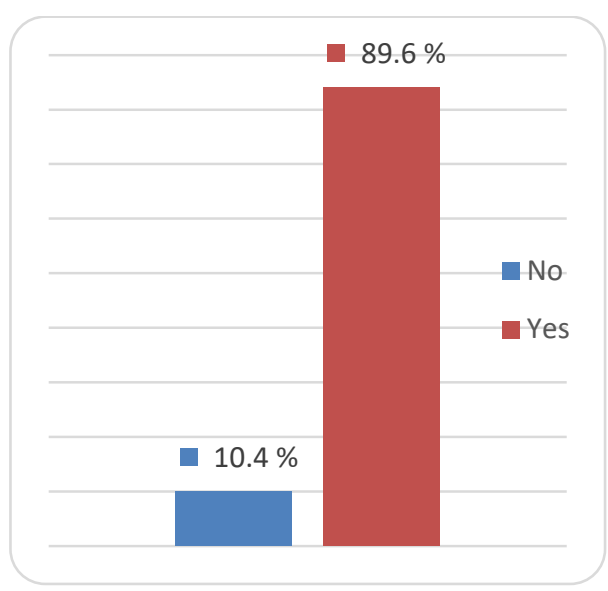

Fig. 8 Teachers considering lack of face to face interaction as a disadvantage in online teaching

\subsection{Platform/tool used by teachers for online teaching}

A big percentage of teacher's i.e. 85.7\% used What Sapp tool for the online delivery of instruction, while as $56.9 \%$ of teachers used Whatsapp and Zoom platform for online teaching.37.5\% of teachers used Google classroom and Whatsapp, only $6 \%$ of teachers used Google classroom only as an online tool for teaching, $18.75 \%$ teachers other tools not listed here, similar percentage used YouTube and Whatsapp in combination for delivery of instruction (see Fig.9).

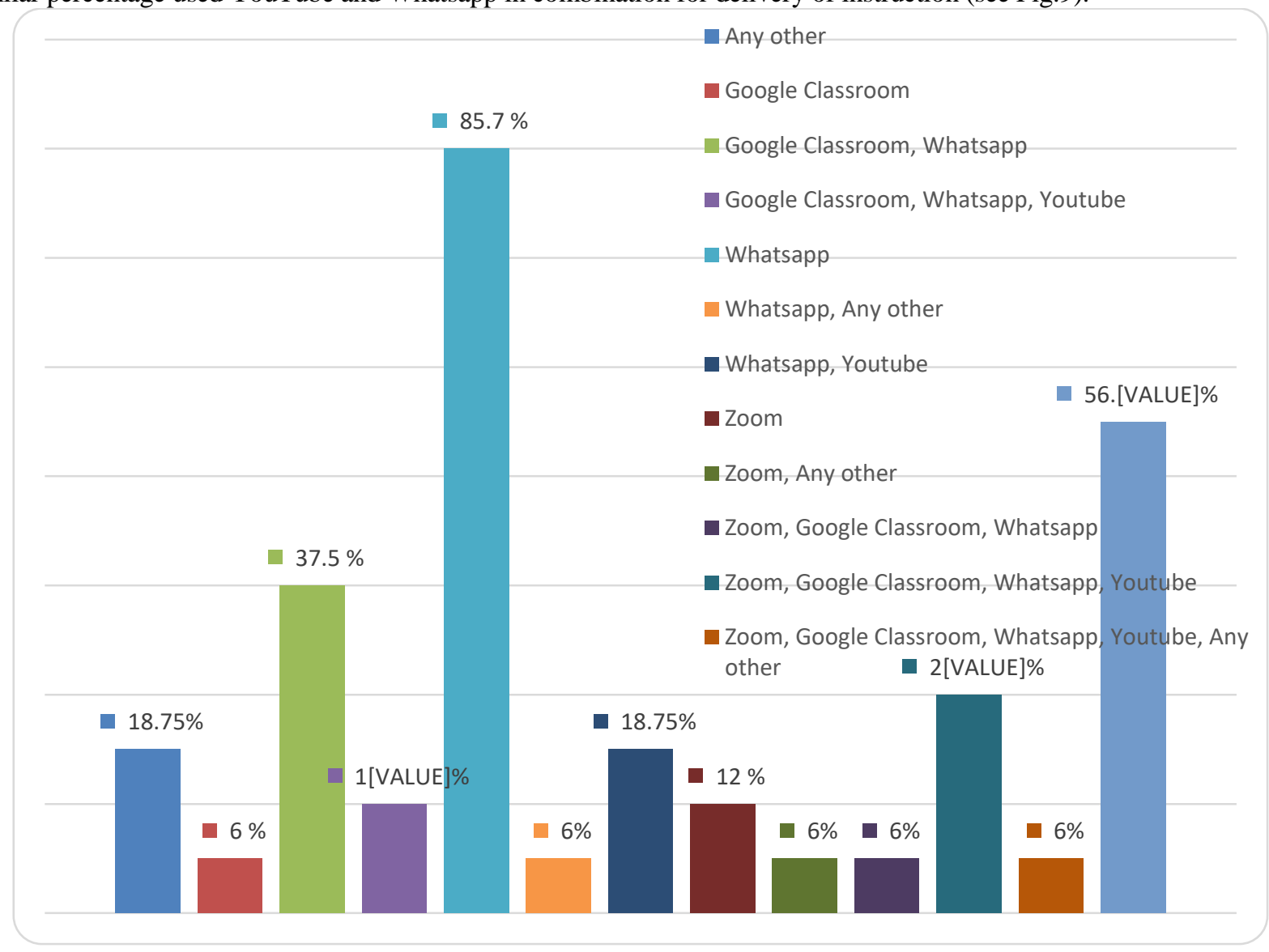

Fig. 9 Platform/tool used by teachers for online teaching 
6.10 Teachers who take care of plagiarism and copyright issues while creating e-content for online teaching

$71.4 \%$ of the teachers reported that they take care of plagiarism and copyright issues, $28.6 \%$ of the teachers say they don't take care or lack awareness about plagiarism and copyright violations (see Fig.10).

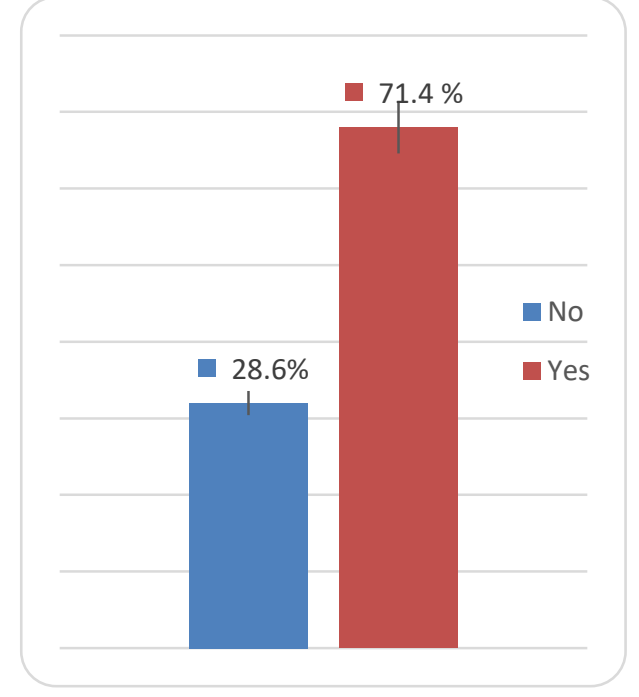

Fig.10 Teachers who take care of plagiarism and copyright issues while creating e-content for online teaching

6.11 Creating e-content online takes more time than face to face classroom teaching

89.8\% teachers agreed to the fact that creating e content requires more time and effort than face to face classroom teaching while as only $10.2 \%$ of the teachers disagreed with the fact (see Fig.11).

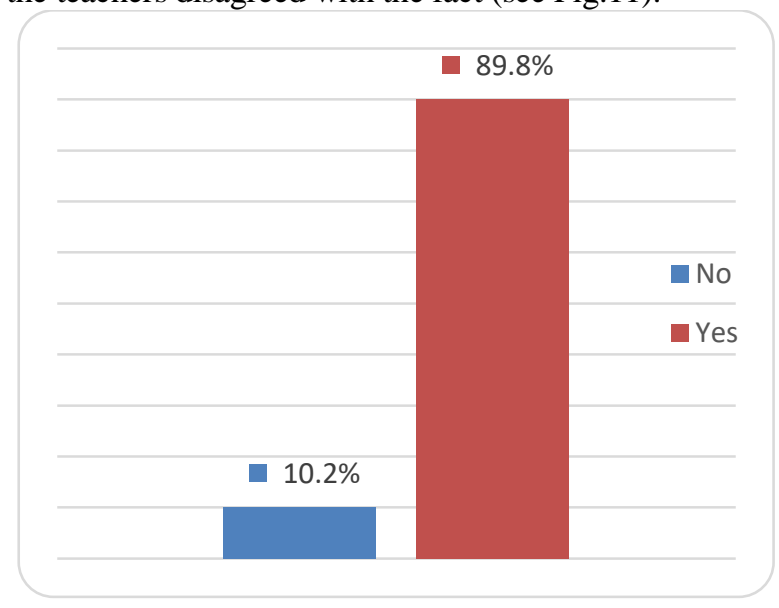

Fig.11 Creating e-content online takes more time than face to face classroom teaching.

\subsection{Teachers experience with online teaching and creating e-content}

The data about teachers experience or ease with online teaching and creation of e content revealed that majority of the teachers i.e.; $42.5 \%$ rated online teaching and content creation as very difficult for them, 34\% rated their experience as difficult, $19.5 \%$ as easy and only $4 \%$ of teachers rated their experience as very easy (see Fig.12). 


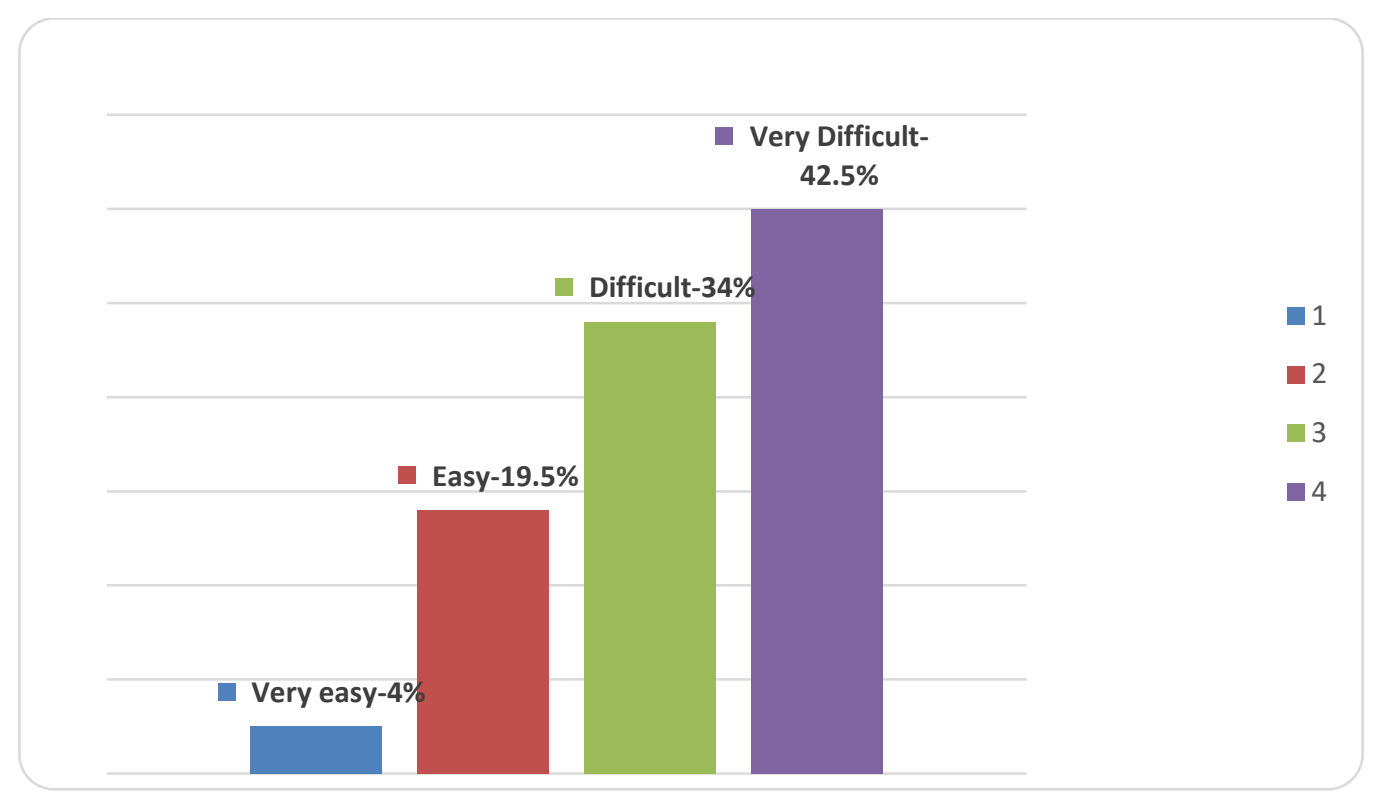

Fig.12 Teachers experience with online teaching and creating e-content.

\section{Results}

The results of this survey paper indicate that teachers are facing technical difficulties in using online platforms for delivery of instruction as well as in creating e-content. The survey results also indicate that Internet connectivity and low bandwidth is a bottleneck in online teaching and teachers are finding it difficult to deliver online lectures on low bandwidth. Teachers also revealed the fact that they lack computer skills required for online teaching as well as creating digitised material for teaching and felt need for proper guidelines or trainings on the use of online tools/platforms for online teaching and e-content creation. Study also shows that the students are not taking online teaching seriously and are there is low response to assignments assigned to them by teachers online. Students have to make big adjustments to make transition from classroom learning to online learning. Teachers also feel that human touch and direct interaction is lacking in this mode of teaching making it difficult for them to teach students. When we compared different common available tools used by teachers for online teaching, it was found that Whatsapp is the most used tool followed by Zoom, Google classroom, YouTube and other tools not specified here. When asked about plagiarism and copyright issues most of the teachers responded positively that they are taking due care of these issues while creating their content. Most of the teachers agreed that creating e-content takes more time and effort than classroom teaching. When we asked teachers to rate their experience about creating e-content or using online modes for teaching in terms of difficulty, majority of the teachers rated their experience as very difficult, followed by difficult and only a small percentage considered it an easy or very easy experience.

\section{Recommendations}

On the basis of research study and after taking into account the challenges faced by teachers in using online platforms/tools for teaching, there are some recommendations that can help in effective online teaching. Some of them are;-

1. There is need for professional development of teachers with emphasis on use of ICT tools in creating, sharing, disseminating content and use of online modes of teaching learning process.

2. Teacher education programmes must include ICT integration in teaching as an important component to enable teacher candidates for the use of ICT based environment for teaching.

3. ICT infrastructure must be strengthened in our country to support online teaching as an alternative mode of teaching at the times of crisis.

4. Teachers must be provided with detailed guidelines to help them while using online tools/platforms for teaching.

5. Internet bandwidth must be sufficient to support the high data rate to enable video streaming leading to effective teaching and learning.

6. Digital divide must be taken into consideration as there is some portion of the population which doesn't have access to Internet and digital devices. 
7. Community and parents must be involved to increase awareness in students and their parents about the use of online tools for learning so that efforts of teachers don't go waste.

\section{Conclusion}

Although the research methodology used has some limitations like self reporting and non probabilistic sampling but the study can help in understanding the perspectives of teachers delivering education online and issues faced by them in the process. The emergent unplanned crisis has witnessed the mode of online teaching-learning as the only possible alternative to the traditional classroom teaching. The use of online platforms for online teaching and learning should not be considered as a viable solution just during the emergency situations, but this mode can be used in parallel with classroom teaching as a blended learning model of education after the situation eases out. The data samples collected by electronic means and subsequently examined gives a clear indication about the need of professional development of teachers with special emphasis on digital literacy and use of ICT platforms /tools for teaching. It also suggests that ICT infrastructure must be strengthened worldwide and particularly in developing countries where digital divide is preventing socioeconomically disadvantaged sections to be benefited from online education thus depriving them of basic right to education. Technology can't replace the teachers but it can equip them with skills and knowledge to face any challenging situation similar to current one. The objectives of the study to investigate the teachers' perspective and issues faced by teachers while teaching online has been achieved and based on the results, some of the important recommendations are mentioned in this paper. Based on this study it can be concluded that exacerbating loss of education in the pandemic to students can be reduced to a large extent by online education.The main advantages of online teaching is flexibility and ubiquitous access while requirement to buy digital devices and internet connection are the main challenges. Future research will explore alternative technologies or improved methodologies to extend the scope of this study beyond various limitations imposed by current environment.

\section{Acknowledgements}

We express our deep sense of gratitude to the teachers, who cooperated with us in providing the feedback required for this study. We also express our sincere thanks to Prof. Javed Musarrat (Hon’ble Vice Chancellor) and Prof. Iqbal Parwez (Dean Academics) of BGSB University for their continuous support and motivation.

\section{References}

[1] M. Palacios Cruz, E. Santos, M. A. Velázquez Cervantes, and M. León Juárez, “COVID-19, a worldwide public health emergency,” Revista Clinica Espanola. Elsevier Doyma, 2020, doi: 10.1016/j.rce.2020.03.001.

[2] “Covid-19 Blessing In Disguise For Indian Education Sector | Eduvoice.” https://eduvoice.in/covid-19-blessing-in-disguise-forindian-education-sector/ (accessed May 28, 2020).

[3] “The impact of COVID-19 on education | VOX, CEPR Policy Portal.” https://voxeu.org/article/impact-covid-19-education (accessed May 28, 2020).

[4] “COVID-19: Creating a paradigm shift in India’s Education System.” https://economictimes.indiatimes.com/blogs/etcommentary/covid-19-creating-a-paradigm-shift-in-indias-education-system/ (accessed May 28, 2020).

[5] “Impact of COVID-19 on Education System in India.” https://www.latestlaws.com/articles/impact-of-covid-19-on-educationsystem-in-india/ (accessed May 28, 2020).

[6] "How India can transform education in the post-coronavirus world.” https://www.dailyo.in/variety/covid-19-coronavirus-inindia-education-e-learning-schools-higher-education/story/1/32916.html (accessed May 28, 2020).

[7] “The importance of school education in child development - EducationWorld.” https://www.educationworld.in/the-importanceof-school-education-in-child-development/ (accessed May 28, 2020).

[8] "COVID-19 effect: Schools shut, colleges conducting online classes; get latest updates here." https://www.shiksha.com/boards/articles/covid-19-effect-schools-shut-colleges-conducting-online-classes-get-latest-updateshere-blogId-32375 (accessed May 28, 2020).

[9] "UNESCO: Over 154 cr students hit by schools,colleges closure due to COVID-19; girls to be worst hit - Times of India." https://timesofindia.indiatimes.com/home/education/news/unseco-over-154-cr-students-hit-by-schoolscolleges-closure-due-tocovid-19-girls-to-be-worst-hit/articleshow/75294123.cms (accessed May 28, 2020).

[10] "Education in the time of Covid-19: How institutions and students are coping | Business Standard News.” https://www.businessstandard.com/article/education/education-in-the-time-of-covid-19-how-institutions-and-students-are-coping120043001575_1.html (accessed May 28, 2020).

[11] “India Must Treat the Internet as a Public Utility During COVID 19, and After.” https://thewire.in/tech/india-must-treat-theinternet-as-a-public-utility-during-covid-19-and-after (accessed May 28, 2020).

[12] "Most teaching is going remote. Will that help or hurt online learning?" https://www.insidehighered.com/digitallearning/article/2020/03/18/most-teaching-going-remote-will-help-or-hurt-online-learning (accessed May 28, 2020).

[13] "Coronavirus meant teachers had little training for online classes." https://www.usatoday.com/story/news/education/2020/04/17/coronavirus-teachers-online-class-school-closures/2972529001/ (accessed May 28, 2020). 
[14] “How Would COVID-19 Affect Indian Higher Education? | Eduvoice.” https://eduvoice.in/how-would-covid-19-affect-indianhigher-education/ (accessed May 28, 2020).

[15] "Covid lockdown has come as a blessing in disguise, says VC of Amity University - The Hindu BusinessLine." https://www.thehindubusinessline.com/news/education/covid-lockdown-has-come-as-a-blessing-in-disguise-says-vc-of-amityuniversity/article31422081.ece (accessed May 28, 2020).

[16] “COVID-19: Indian Internet infra not prepared for shift to online teaching-learning, says QS report - The Economic Times.” https://economictimes.indiatimes.com/tech/internet/covid-19-indian-internet-infra-not-prepared-for-shift-to-online-teachinglearning-says-qs-report/articleshow/75269679.cms?from=mdr (accessed May 28, 2020).

[17] "cyber security news: Zoom app vulnerable to cyber attacks, says CERT-India; issues advisory on safety measures, IT Security News, ET CISO.” https://ciso.economictimes.indiatimes.com/news/zoom-app-vulnerable-to-cyber-attacks-says-cert-indiaissues-advisory-on-safety-measures/74959554 (accessed May 28, 2020).

[18] "Digital education during COVID-19 lockdown not for all - cnbctv18.com.” https://www.cnbctv18.com/technology/digitaleducation-during-covid-19-lockdown-not-for-all-5785491.htm (accessed May 28, 2020).

[19] N. Al.Ragawi, “Obstacles and Opportunities for Yemeni Students to Use Mobile Learning,” Int. J. E-Learning Educ. Technol. Digit. Media, vol. 3, no. 4, pp. 161-173, 2017, doi: 10.17781/p002386.

[20] S. Appana, “A Review of Benefits and Limitations of Online Learning in the ...,” Int. J. E-learning, vol. 7, no. 1, pp. 5-22, 2008.

[21] T. Volery and D. Lord, “Critical success factors in online education,” Int. J. Educ. Manag., vol. 14, no. 5, pp. 216-223, 2000, doi: 10.1108/09513540010344731.

[22] B. Bomsdorf, “Adaptation of Learning Spaces : Supporting Ubiquitous Learning in Higher Distance Education,” Mob. Comput. Ambient Intell. Chall. Multimed. Dagstuhl Semin. Proc., vol. 5181, p. The challenge of mu, 2005, [Online]. Available: http://drops.dagstuhl.de/opus/volltexte/2005/371/.

[23] T. Nguyen, "The Effectiveness of Online Learning: Beyond No Significant Difference and Future Horizons," vol. 11, no. 2, pp. 309-319, 2015.

[24] R. H. Huang, D. J. Liu, A. Tlili, J. F. Yang, and H. H. Wang, "Handbook on facilitating flexible learning during educational disruption: The Chinese experience in maintaining undisrupted learning in COVID-19 Outbreak,” Smart Learn. Inst. Beijing Norm. Univ. UNESCO, pp. 1-54, 2020, [Online]. Available: https://iite.unesco.org/news/handbook-on-facilitating-flexiblelearning-during-educational-disruption/.

\section{Authors' Profiles}

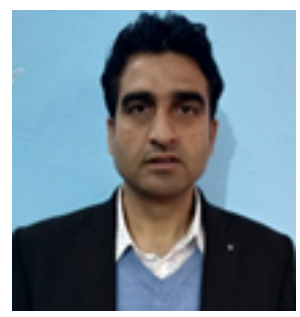

Malik Mubasher Hassan: Received his B.Tech degree from the University of Jammu followed by M.Tech degree from NIT Srinagar in 2007. He is presently serving as Principal University Polytechnic Baba Ghulam Shah Badshah University (BGSBU) Rajouri (J\&K), India-185234. Former Head, Dept. of ITE BGSB University Rajouri. His research interests include communication systems, optical wireless, computer Networks, data mining and ICT.

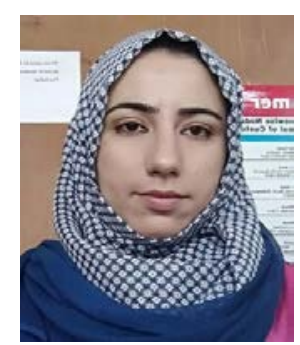

Tabasum Mirza: She has received a Masters Degree in Computer Applications from University of Kashmir in 2008. She is presently working as Lecturer in the Department of Computer Science, School Education, Government of Jammu and Kashmir, India. She has a 6.5 years experience of working in JK Bank Pvt. Ltd. Her specialization is software Engineering, Java Programming, Data Mining and e-learning.

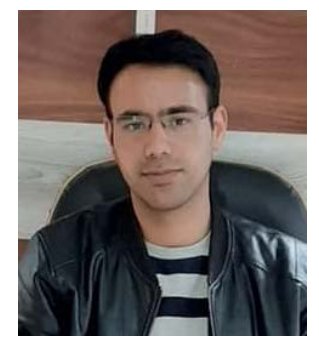

Dr. Mirza Waseem Hussain: He has received a Masters Degree in Computer Applications from University of Kashmir in 2012 and he was awarded Ph.D in "Congestion Control in Computer Networks" in 2017 from BGSB University Rajouri-J\&K. He is presently working as Lecturer in the Department of Computer Science, School Education, Government of Jammu and Kashmir, India. His research interests are computer networks, neural networks, Data Mining and e-learning.

How to cite this paper: Malik Mubasher Hassan, Tabasum Mirza and Dr. Mirza Waseem Hussain. " A Critical Review by Teachers on the Online Teaching-Learning during the COVID-19 ", International Journal of Education and Management Engineering (IJEME), Vol.10, No.5, pp.17-27, 2020. DOI: 10.5815/ijeme.2020.05.03 